zinc. The ability of zinc to decompose oxide of lead may $\mid$ of Paraffin Oils on Metals," by Dr. S. Macadam. He comes aromatic principles that several phenomena are due, such

Table of Decomposition.

Oxygen.

Zinc.
Lead.

The metal whose oxide is decomposed more easily is placed below. When you find this list extended, as is generally
the case in text books, so as to include all the metals arthe case in text books, so as to include all the metals arcopy it, and post it up in the dyebouse.

oxide of lead and acetic acid is greater or less than that which exists between that oxide and some other acid, for
example, sulphuric.

Experiment 4.-To the teaspoonful of acetate of lead which vou poured into a wine glass and kept covered, add about a
tablespoonful of pure water, and then add a few drops of sulphuric acid. The solution, previously clear, instantly be-
comes turbid, and a beavy white powder sinks to the comes turb
bottom.

Explanation.-This powder is the insoluble sulphate of lead. Sulphuric, the master acid, unites with the oxide of
lead, liberating the acetic acid, which remains in the solution. phuric Acid=Sulphate of Lead+Acetic Acid. or, further phuric Acid = Sulphate of Lead + Acetic Acid; or, further
aid the memory in the form of a tahle of decomposition:

Oxide of Lead.

Sulphuric Acid.
Acetic Acid.

When an acid combines with an oxide of a metal the recomposition of one salt, the acetate of lead, by a stronger acid than the ace

The affinity of the oxides of zinc and of lead for the acetic, their attraction for vegetable dyes is too weak to merit bu their attraction for vegetable dyes is too weak to merit your attention now. The oxide of aluminum, known as alumina,
bas, on the contrary, a powerful attraction for those dyes,
as a few days experience at the dye vat sill teach you. as a few days' experience at the dye vat will teach you.
But this attraction for the several vegetable coloring principles is not equal, and you may measure its relative power as
readily as you can that of an oxide for an acid. Nor need you specially prepare your alumina. You have but to take advantage of its preparation for use on a large scale, and other goods. With this piece you may test the relative
attraction of alumina for at least three important vegetable attraction of alumina for at least three impor

Wiperiment 5.-First immerse the cloth mordanted with alumina in a decoction of quercitron bark. 'I'his imparts to it a fast yellow color. Wash well, then put it into a hot
decoction of logwond. The color of the cloth will gradually be changed from yellow to purple. Rinse, and immerse

ple cloth will become red.
Explanation. - The yellow compound of alumina and querExplanation immersed in the decoction of logwood, was
decomposed; the quercitron being set free by the greater attraction existing between logwood and alumina. So when the purple cloth is kept in the hot solution of madder, the
superior attraction of this dye for alumina sets free the log wood.

You are, therefore, with alumina and the three dyes, able
to make the following table of decomposition: Alumina.
Madder,
Logwood,
Quercitron.

The dye which has the greatest attraction for the metalli oxide being placed first under it, the others following in order.
The formation of litharge in the first experiment illustrates
how oxides are composed. bow oxides are composed. The production of the acetate of lead in the second experiment, by the union of the oxide the combin ation of an acid with a metallic oxide. The taking advantage of the superior affinity existing between zinc and oxygen, is a case of chemical decomposition well
wortby of repetition. It is one of a large number of in-
teresting transformations of the acetate of lead in the fourth experiment by the stronge tion of the insolnble sulphate of lead, and the consequent setting free of the acetic acid. elucidate the transformations
of mineral salts; while the fifth experiment carries these of mineral salts; while the fifth experiment carries these
transformations among the coloring matters, and demon strates that the laws of decomp
of the dye vat. - Textile Record.

\section{ON THE ACTION OF OILS ON METALS.}

By Wirliak Henry Watson, F.C.S., etc.

At the Plymouth meeting of this association I brought
forward the results of some experiments, showing the ac forward the results of some experiments, showing the ac
tions of various oils on copper, and the conclusions arrived at were briefly these:
1 . That of the whole of the oils used, viz., linseed, olive colza, almond, seal, sperm, castor, neatsfoot, sesame, and paraftin, the samples of paraffin and castor oils had the least
action, and that sperm and seal oils were next in order of action, and that sperm and seal oils were next in order of
inaction. inaction.
2. That the appearances of the paraffin and the copper
were not changed after 77 days' exposure. w. That different oils produce compounds with copper
3. The varying in color, or in depth of compounds with copper
rendering compirative determinations of their action on that metal from mere observations of their appearances im
possible. possible.
I was disposed to conclude that these experiments would
indicate indicate the relative action of the olls on other metals, throughout, but that the variations would be proportionate
between the different oils.

Since the publication of these results, however, an inter-
esting paper has appeared (Pharm. Journ.), "On the Action * Read before the Chemical Section of the Britieh Association, swansea
Meetmn, 1880 . to the same conclusion as myself with regard to their action as vertigo, paiv in the head, and nausea, which are pro
on copper, but referring to iron, says "it is slightly affected duced by certain tobaccoes, either poor in nicotine or des on copper, but referring to iron, says "it is slightly affected duced by certain tobaccoes, either poor in nicotine or des-
by paraffin oil, and on ten days' contact the oil becomes titute of it, while otber tobaccoes, rich in nicotine, do not deeper in color and throws down a fine ferruginous sedi- produce any analogous effects.
ment." Owing to this, I have lately made experiments on 6. The proportion of prussic acid and aromatic princihe action of the same oils as those previously used on ples contained in tobacco smoke varies in different to copper, on iron, and the results, which are the subject of here is no relation between the action of an oil on copper

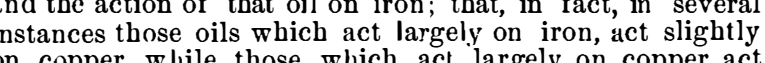
ittle on iron. Of course the actual extent of action of the hane oil (with the exception of paraffin) is greater on coppe
han. In addition to the oils used in ryy experiments on copper cating oil prepared by the Dee Oil Company, near Chester. The followingr of
days' exposure:

1. Neatsfoot.-Considerable brown irregular deposit on 2. Colza.-A slight brown substance suspended in the oil, which is now of a reddish brown color. A few irregular
markings on the metal. 3. sperm.-A slight br

ings on the metal. Oil of a dark brown color. metal.
5. Olive.-Clear and bleached by exposure to the light: and air. The appearance of metal same as when first im mersed.
6eal. A few irregular markings on metal. The oil ree from deposit, but of a bright clear red color. 8. Almond.-Metal bright. Oil bleached and free from deposit.

9. Castor.-Oil considerably more colored (brown) than when first exposed. Metal bright.
10. Paraffin.-Oil bright yellow and contains a little brown deposit. The upper surface of the metal on being
removed is found to have a resinous deposit on it. 11. Special Lubricating
ot perceptibly changed.

The samples were then chemically examined, and the ere as follows:

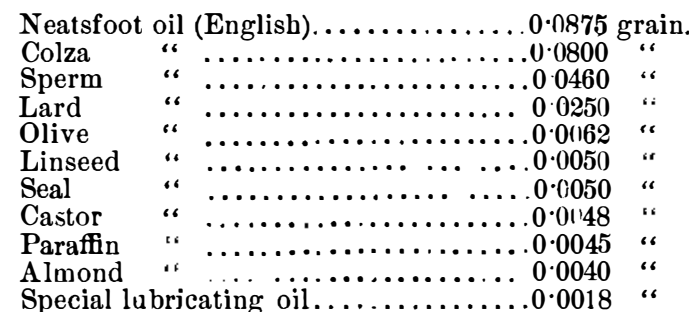

For comparison, the following are the results obtained of a the action of these oils on copper, as previously communi-

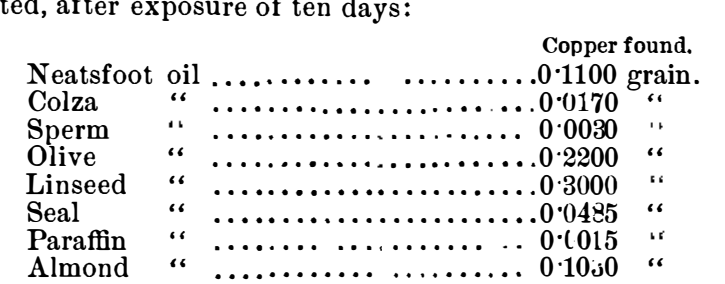

Owing to the length of exposure being different in the two series, we cannot fix on the actual differences in the
rate of action of any of the oils on the 1 wo metals. Howcoer, it is slown that almond oil, which acted largely on
copper acts very slightly on iron; in fact, with the exception of the paratin and special lul, incating oil (a mineral preparation), it acted less than any of the other oils on iron. f various other oils; thus, while sperm oil acts slightly o copper, it acts considerably, compared with the others, on bracketed as baving about the same and very little action on ron, while linseed, olive, neatsfoot, almond and seal have he greatest action on copper.

PRUSSIC ACID AND A NEW ALKALOID IN
TOBACCO SMOKE.

DR. LE Bon has communicated to the Journal de Ther peutique a paper "On the Existence in Tobacco Smoke of New Alkaloid." He comes to the following conclusions
1. The principles of tobacco smoke, which are condensed by cooling in the mouth and lungs or in the apparatus monia, various tarry matters, coloring substances of amacid combined with bases, and very odorous and very poisubstances are found mixed with a large proportion of the vapor of water and of various gaseous compounds, princi
pally the oxide of carbon and carbonio acid. 2 . The liquid resulting from the condensation of the pre-
pally the oxide or and and carbonio acid. 2. The liquid resulting from the condensation of the pre-
ceding substances is endowed with extremely poisonous properties. It suffices to inject very small quantities into the
circulatory system of an animal, or to cause it to be respired
for some time, to induce death, after the exhibition of various signs of paralysis.

present time have been attrihuted solely to nicotine also due to prussic acid and to various aromatic princples. especially an alkaloid, collidine. This is a liquid sence of which bad been exhibited in the distillation of various organic matters, but the physiological properties of
which were entirely unknown. It contributes in great part to giving its odor to tobacco smoke; and so penetrating
is its perfume that but a single drop suffices to impart a is its perfume that but a single drop suffices to impart a
very strong odor to a large quintity of water. 4. Collidine is an alkaloid as poisonous as nicotine. The symptoms of paralysis. Only a few instants breathing it 5. It is to the presence of prussic acid and the variou
induces muscular debility and vertigo.
7. The black stmi fluid matter which condenses in the interior of pipes and cigar bolders contains all the substances enumerated, and especially large quantities of ni-
cotine. It is extraordinarily poisonous, two or three drops ufficing to kill an animal of small size.

8. The combustion of tobacco destroys only a small part being absorbed by smokers, and which we have determined in our experiments, varies according to the conditions in which these latter are placed. It is scarcely ever less than The quantity of ammonia absorbed at the same time is about 9. Of the different modes of smoking, that in which the mount of nicotine and the various other principles that in which the proportion is least, is smoking the nargh r pipe with a long tube in the open air, without respiring 10. Nicotine kills animals inst: 1 tly in doses of two or three drops, but in infinitely smaller dosers it causes paralysis
and death. A frog introduced into a vessel containing an aqueous solution of nicotine at one-two-hundred thousandth, or about one drop to a liter of water, succumbs in some
hours. The same occurs if the frog be placed under a funnel ntaining a single drop of nicotine in a roll of cotton wool. The vapor disengaged from nicotine while boiling kills ani-
mals instantly, without leaving them time to move. 11. Tobacco smoke contains about eight liters of oxide of carbon per 100 grammes of tobacco burned. Our experiments prove that it is not to this gas that it owes its poison-

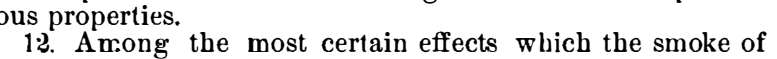
obacco determines in the long run in man, may be mentioned visual dislurbances, palpitations, tendency to vertigo,
and especially diminution of memory.

\section{LIQUEFIED OZONE.}

IT bas been recently found by MM. Hautefeuille and Chappuis that the production of ozone in oxygen by the
silent electric discharge in $M$ Berthelot's apparatus for that purpose is greatly influenced by temperature. Thus in passing from $20^{\circ}$ to $-55^{\circ}$ the proportion of ozone obtained was
nearly quintupled. Increase of pressure has a like effect, but much less in amount for each temperature. By reason of these observations the authors have been enabled to submit portions of larkely ozonized oxygen to the action of inknown mercury acts by pressure on a gas in a strong capillary tube). The capillary tube was kept at a temperature of assumed a blue color, deepening to indigo blue when the sudden decompression or release of pressure from 75 atmospheres, gives rise to a thick, blue mist, a certain sign of
liquefaction of the ozone. To get a corresponding mist with pure oxygen requires a previous compression to 3.0 atmo to liquefy than carbonic acid. It would appear, further that ozone is to be numbered among explosive gases. If the mixture of oxygen and ozone referred to be not compressed
slowly and kept cool, the ozone is decomposed with libera. tion of heat and light. A strong detonation is heard, ac-
companied by a yellowish flash. The blue color (it is remarked) is as characteristic of ozone as the odor of the gas, ness of the gas be looked through.

ACTION OF SULPHURIC ACID ON PLATINUM. By SchedRer-KestNer.

THE action of chamber vitriol on the platinum retorts used in the process of concentration is due to the presence of a
very minute trace of oxides of nitrogen, which give scarcely ny reaction with ferrous sulphate, but may be detected by means of the blue color formed by diphenylamine. The
solvent action is greater the greater the concentration of the $\lceil$ acid. The oxides of nitrogen exist in the oil of vitriol in presence of selenium and sulphurous anbydride, and are apparently in a state of stable combination, since they are not
expelled during the process of concentration, whereas all the
sulphurous anhydride is given off. nitrogen oxides, which appear to act as intermediate agents in the oxidation of the platinum at the expense of the oxygen of the sulphuric acid, is consequently sufficient to cause conremains in contact with it. If, however, the oil of vitrinl be
remalo previously boiled with a little ammonium sulphate, all the oxides of nitrogen are destroyed, and the action on the
platinum is prevented. Perfectly pure sulphuric acid does not attack platinum even when beated with it in closed tubes not attack platinum even when leated with it in
at the boiling point of sulphur.-Compt. Rend.

\section{SULPHUR IN COAL}

By W. WALLACE.

Ir has been assumed that sulphur exists in coal chiefly, if
not entirely, as irou bisulphide. Crace-Calvert bas asserted that in some cases it is partly present as sulphates. The author shows that in some coals the sulphur chiefly exists as
an organic compound. The following table shows the rela. tive quantities of total sulphur and that existing as pyrites,
aseuming all the iron found in the ash to have been present

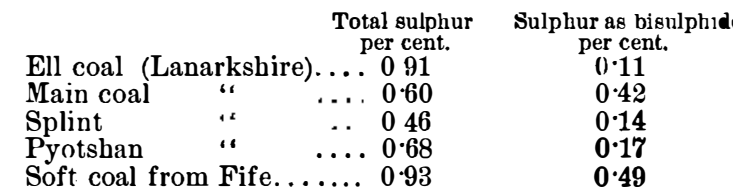

The estimations of sulphur were made by Pattinson's method, and also by fusion with sodium carbonate and po. method to be free from sulphates, the others were not reat part in the smoke. The proportion susceptible in as bisulphnde: 